\title{
A Simple Preparation Method of Thin-Layer Standard Samples with Activated Carbon for the Multi-Element Determination of Airborne Particulate Matter by X-Ray Spectrometry
}

\author{
Masaaki IwATSUKI*, Tomohiro KYoTANI* and Satoshi KoshIMIzU** \\ *Department of Applied Chemistry and Biotechnology, Faculty of Engineering, Yamanashi University, \\ Takeda, Kofu 400, Japan \\ ** Yamanashi Institute of Environmental Sciences, Kenmarubi, Kamiyoshida, Fujiyoshida 403, Japan
}

\begin{abstract}
Thin-layer standard samples for the X-ray fluorescence (XRF) analysis of airborne particulate matter have been conveniently prepared by impregnating activated-carbon powder with standard solutions of the elements of interest and by drying it. Different amounts of standard solutions of the elements of $1.00 \mathrm{mg} \mathrm{ml}^{-1}$ each and a $0.01 \%$ surfactant (Tween 85 ) solution of $1.5 \mathrm{ml}$ are added to a fine powder of activated carbon of $5-10 \mathrm{mg}$ on a hydrophilized poly(tetrafluoroethylene) membrane filter. The suspension of carbon is dispersed by blowing air from a pump for 2-3 min without bubbling and dried by IR irradiation for $10 \mathrm{~min}$ without filtration. This filter with carbon is impregnated with a $0.02 \%$ polycarbonate dichloromethane solution of $0.3 \mathrm{ml}$, followed by air-drying. Inductively coupled plasma atomic emission spectrometry of digestates from the prepared samples gave good recoveries of all the measured elements. The XRF intensities of the samples prepared repeatedly had reasonable reproducibilities. Calibration graphs with good linear relationships were constructed for 21 elements in the range of $0-50 \mu \mathrm{g}$. The standard samples prepared were successfully used for the multi-element XRF determination of airborne particulate matter, in good agreement with the results of instrumental neutron activation analysis.
\end{abstract}

Keywords Thin-layer standard sample, activated-carbon carrier, X-ray fluorescence analysis, multi-element determination, airborne particulate matter

The multi-element determination of airborne particulate matter has been carried out by several methods: i.e., instrumental neutron activation analysis (INAA) ${ }^{1}, \mathrm{X}$-ray fluorescence (XRF) analysis ${ }^{2}$, inductively coupled plasma atomic emission spectrometry ${ }^{3}$ and mass spectrometry $^{4}$ (ICP-AES and ICP-MS), etc. ICP-AES and ICP-MS are more sensitive for some elements than XRF analysis, but are limited to solution samples, which require time-consuming and tedious effort for their preparation. INAA has attractive advantages of high sensitivity and nondestructiveness, but requires an atomic reactor and measurements at an interval over an extended period of up to one month in order to avoid interferences. XRF analysis appears to be the most attractive method for the determination of major and minor elements in airborne particulate matter, because of its simplicity, rapidity, high precision and nondestructiveness, provided adequate standard samples are obtainable. However, the preparation of thin-layer standard samples for XRF analysis is not easy. Several methods using coprecipitation ${ }^{5-9}$, vacuum evaporation $^{9,10}$, impregnated paper ${ }^{11,12}$, an aerosol generator ${ }^{12-15}$, polymer film ${ }^{16}$, precipitation on a polyamide film substrate $^{17}$, deposition of certified reference materials on filters ${ }^{18}$ and a cast film containing a radioactive tracer ${ }^{19}$ have been used for the preparation. 'Although the methods using impregnated paper and precipitation on a film are simple and convenient, heterogeneity in the distribution of elements in the sample can cause significant errors. The last method needs special attention to its radioactivity. In the remaining methods described above, the amounts of analyte elements in each sample were determined by use of a balance, which may give large errors for such micro amounts, or by other quantitative methods, such as atomic absorption spectrometry (AAS) and ICP-AES, after decomposition of the sample; applicable elements are also often limited with these methods. Consequently, the problem of the standard samples limits the application of XRF methods to airborne particulates analysis. The present paper describes a simple and convenient method for the preparation of thin-layer standard samples with activated carbon for the multi-element XRF determination of airborne particulate matter collected on a filter. A comparison between the analytical results of real samples by the XRF method using prepared standard samples and those by INAA is also given.

\section{Experimental}

\section{Samples, reagents and filters}

Airborne particulate samples were collected on cellulose nitrate membrane filters (Advantec, A300A110C, 
$3.0 \mu \mathrm{m}$ in pore size, $110 \mathrm{~mm}$ in diameter) for $13 \mathrm{~d}$ (air volume $374.4 \mathrm{~m}^{3}$ ) by a low-volume air sampler with a cyclone classifier $(<10.0 \mu \mathrm{m})$ (Shintaku Machine Manuf., Model S-2) with a flow rate of $201 \mathrm{~min}^{-1}$ in Yamanashi Prefecture, Japan in 1995. Pieces of $47 \mathrm{~mm}$ in diameter cut from the filters were subjected to XRF analysis, and semicircular pieces cut from the filters to INAA. Other samples were collected on hydrophilized poly(tetrafluoroethylene) (PTFE) filters (Millipore, Omnipore JA, $1.0 \mu \mathrm{m}$ in pore size, $47 \mathrm{~mm}$ in diameter) or regenerated cellulose filters (Fuji Photo Film, FR-100, $1.0 \mu \mathrm{m}$ in pore size, $47 \mathrm{~mm}$ in diameter) for $7-12 \mathrm{~d}$ by a low-volume air sampler with a satellite unit (Rupprecht \& Patashnick Co., Partisol Model 2000) with a flow rate of $16.71 \mathrm{~min}^{-1}$ by turns every $5 \mathrm{~min}$ for the hub $(<10.0 \mu \mathrm{m})$ and satellite $(<2.5 \mu \mathrm{m})$ units at Yamanashi University in 1996, and subjected to XRF analysis. The amounts of the samples subjected to XRF analysis were 0.16 $-2.7 \mathrm{mg}$ per analyzed area of $32 \mathrm{~mm}$ in diameter, i.e., $20-330 \mu \mathrm{g} / \mathrm{cm}^{2}$.

Activated-carbon powder (Merck) was ground with a tungsten carbide mortar and washed with nitric acid; its fine powder of $<1.0 \mu \mathrm{m}$ was collected by a sedimentation method. All of the reagents used were of analyticalreagent grade. De-ionized and distilled water was used throughout. A $0.01 \%$ surfactant (Tween 85 ) solution was prepared by dissolving its reagent (Wako Pure Chemical Industries, Osaka) in water. A $0.02 \%$ polycarbonate dichloromethane solution was prepared by dissolving its resin powder (Teijin Chemical Industries) in dichloromethane. A $0.02 \%$ poly(methyl methacrylate) acetone solution was prepared by dissolving its resin in acetone. A $0.02 \%$ cellulose acetate acetone solution was prepared by dissolving its resin powder (Wako Pure Chemical Industries, Osaka) in acetone.

Standard solutions of sodium, magnesium, sulfur, chlorine, potassium, chromium, cobalt, bromine and cadmium $\left(1.00 \mathrm{mg} \mathrm{ml}^{-1}\right)$ were prepared by dissolving $\mathrm{NaCl}, \mathrm{MgSO}_{4} \cdot 7 \mathrm{H}_{2} \mathrm{O}, \mathrm{K}_{2} \mathrm{SO}_{4}, \mathrm{NaCl}, \mathrm{KCl}, \mathrm{K}_{2} \mathrm{Cr}_{2} \mathrm{O}_{7}$, $\mathrm{Co}\left(\mathrm{NH}_{4}\right)_{2}\left(\mathrm{SO}_{4}\right)_{2} \cdot 6 \mathrm{H}_{2} \mathrm{O}, \mathrm{NaBr}$ and $\mathrm{CdSO}_{4}$, respectively, in water. Standard solutions of vanadium, iron, nickel, copper, zinc and lead $\left(1.00 \mathrm{mg} \mathrm{m}^{-1}\right)$ were prepared by dissolving $\mathrm{NH}_{4} \mathrm{VO}_{3}, \mathrm{Fe}\left(\mathrm{NH}_{4}\right)\left(\mathrm{SO}_{4}\right)_{2} \cdot 12 \mathrm{H}_{2} \mathrm{O}$, $\left(\mathrm{NH}_{4}\right)_{2} \mathrm{Ni}\left(\mathrm{SO}_{4}\right)_{2} \cdot 6 \mathrm{H}_{2} \mathrm{O}, \mathrm{CuSO}_{4} \cdot 5 \mathrm{H}_{2} \mathrm{O}, \mathrm{ZnSO}_{4} \cdot 7 \mathrm{H}_{2} \mathrm{O}$ and $\mathrm{Pb}\left(\mathrm{NO}_{3}\right)_{2}$, respectively, in $\mathrm{HNO}_{3}(1+11)$ of $10 \mathrm{ml}$ each and by diluting each solution to $100 \mathrm{ml}$ with water. A standard solution of aluminum $\left(1.00 \mathrm{mg} \mathrm{ml}^{-1}\right)$ was prepared by dissolving $\mathrm{AlK}\left(\mathrm{SO}_{4}\right)_{2} \cdot 12 \mathrm{H}_{2} \mathrm{O}$ in $\mathrm{HCl}$ $(1+100)$. A standard solution of calcium $\left(1.00 \mathrm{mg} \mathrm{ml}^{-1}\right)$ was prepared by dissolving $\mathrm{CaCO}_{3}$ in $\mathrm{HCl}(1+5)$, followed by boiling the solution and then diluting it to $100 \mathrm{ml}$ with water. A standard solution of titanium was prepared by dissolving metallic titanium in $\mathrm{HCl}(1+1)$ of $25 \mathrm{ml}$, followed by boiling the solution and then diluting it to $100 \mathrm{ml}$ with $\mathrm{HNO}_{3}(1+2)$ of $0.2 \mathrm{ml}$ and water. A standard solution of manganese $\left(1.00 \mathrm{mg} \mathrm{ml}^{-1}\right)$ was prepared by dissolving metallic manganese in $\mathrm{HNO}_{3}$ of $12.5 \mathrm{ml}$, followed by boiling the solution and then diluting it to $100 \mathrm{ml}$ with water. A standard solution of
Table 1 Conditions of XRF analysis

\begin{tabular}{|c|c|}
\hline X-Ray tube & $\mathbf{R h}$ \\
\hline Tube voltage & $40 \mathrm{kV}$ \\
\hline Tube current & $60 \mathrm{~mA}$ \\
\hline Analyzing crystal & LiF, PET, TAP \\
\hline Detector & FPC \\
\hline PR gas flow & $40 \mathrm{ml} \mathrm{min}^{-1}$ \\
\hline Counting time & $100 \mathrm{~s}$ \\
\hline
\end{tabular}

silicon ( $\left.1.00 \mathrm{mg} \mathrm{m}^{-1}\right)$ was prepared by fusing $\mathrm{SiO}_{2}$ with $\mathrm{Na}_{2} \mathrm{CO}_{3}$ as a flux in a $\mathrm{Pt}$ crucible, and then diluting it to $100 \mathrm{ml}$ with water. A standard solution of arsenic (1.00 mg ml $\mathrm{NaOH}$ of $50 \mathrm{ml}$, adjusting it to $\mathrm{pH} 4$ with $\mathrm{HCl}(1+5)$ and then diluting it to $100 \mathrm{ml}$ with water. A standard solution of yttrium $\left(1.00 \mathrm{mg} \mathrm{m}^{-1}\right)$ was prepared by dissolving $\mathrm{Y}_{2} \mathrm{O}_{3}$ in $\mathrm{HCl}(1+1)$ of $20 \mathrm{ml}$, followed by boiling the solution and then diluting it to $100 \mathrm{ml}$ with water.

Hydrophilized PTFE membrane filters (Millipore, Omnipore $\mathrm{JH}, 0.45 \mu \mathrm{m}$ in pore size and $47 \mathrm{~mm}$ in diameter) were used to support the activated carbon in the XRF analysis, because of their superior resistance against $\mathrm{X}$-ray irradiation.

\section{Apparatus and measuring conditions}

A Shimadzu VF-320A (scanning type) XRF spectrometer with a data processor (DP-32II) was used for measurements of the XRF intensities under the conditions listed in Table 1.

\section{Recommended procedure for the preparation of thin-layer standard samples}

A schematic diagram of the preparation method is shown in Fig. 1. At first, 5-10 $\mathrm{mg}$ of fine powder $(<1.0 \mu \mathrm{m})$ of activated carbon is put on a hydrophilized PTFE membrane filter which is fixed on a ground-glass plate by a fluorescein-coated funnel $(35 \mathrm{~mm}$ in inside diameter). The elements of interest are divided into two groups. Different amounts of $1.00 \mathrm{mg} \mathrm{ml}^{-1}$ standard solutions of silicon, sulfur, chlorine, vanadium, chromium, manganese, bromine and lead (group 1), or of sodium, magnesium, aluminum, potassium, calcium, titanium, iron, cobalt, nickel, copper, zinc, arsenic and cadmium (group 2) and $1.5 \mathrm{ml}$ of a $0.01 \%$ surfactant (Tween 85) solution are added to the carbon powder. The suspension of carbon is dispersed by blowing air from a pump for $2-3 \mathrm{~min}$ without bubbling, and dried by IR irradiation for $10 \mathrm{~min}$ without filtration. The filter with carbon is sandwiched between two PTFE rings ( $39 \mathrm{~mm}$ in inside diameter). A $0.02 \%$ polycarbonate dichloromethane solution of $0.3 \mathrm{ml}$ is dropped on the back side of the filter and air-dried. The thus-obtained thin-layer standard samples can be used for XRF analysis. A blank XRF sample is also prepared in the same way as mentioned above, except for the lack of standard solutions. 


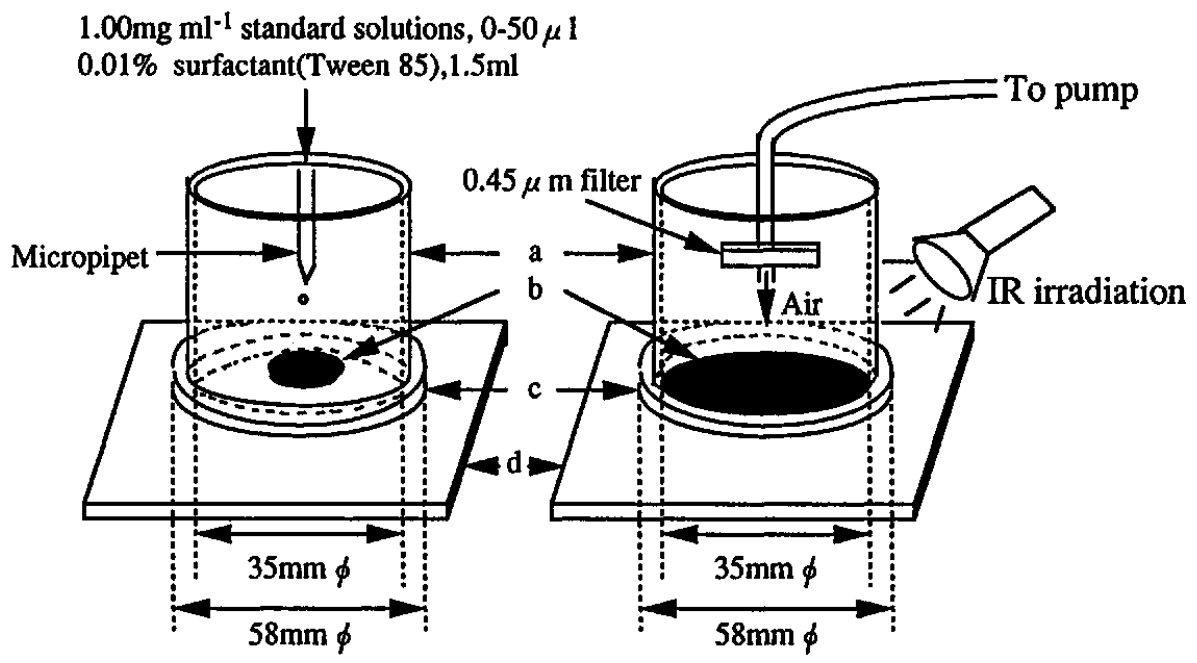

Fig. 1 Schematic diagram of a simple method for the preparation of thin-layer standard samples with activated-carbon for multi-element XRF determination. a, fluorescein-coated funnel; b, activated-carbon powder; c, Omunipore-JH membrane filter $(0.45 \mu \mathrm{m}, 47 \mathrm{~mm} \phi)$; , ground-glass plate.

\section{Measurements of $X R F$ intensities}

The prepared XRF sample was fixed between two aluminum masks with a hole of $40 \mathrm{~mm}$ in diameter, and placed between a titanium mask with a hole of $32 \mathrm{~mm}$ in diameter and a PTFE inner cup in a sample holder. Then, the $\mathrm{K}_{\alpha}\left(\mathrm{L}_{\beta}\right.$ for lead and $\mathrm{L}_{\alpha}$ for cadmium $)$ peak and the background intensities of the elements to be determined were measured. Their net intensities were calculated by subtracting their background intensities at the peak angles as well as the blank values, which were measured for the blank XRF sample. The background intensity $\left[I_{b}(P)\right]$ at the peak angle for each element was calculated as follows. A background profile near to the peak angle was measured using a blank XRF sample. The background intensity ratio $(h)$ at the peak and background angles was determined from the profile. The value of $I_{b}(\mathrm{P})$ was obtained by multiplying the measured intensity $\left[I_{\mathrm{b}}(\mathrm{B})\right]$ at the background angle by $h$; i.e., $\left[I_{\mathrm{b}}(\mathrm{P})\right]=I_{\mathrm{b}}(\mathrm{B}) \times h$.

\section{INAA measurements}

INAA was performed according to the method of Otoshi et al. ${ }^{1,20}$ under the following conditions. Semicircular pieces of the sample filters were sealed in a polyethylene capsule, and irradiated for $5 \mathrm{~min}$ at the $\mathrm{F}$ irradiation hole of Reactor Model TRIGA II at the Institute for Atomic Energy, Rikkyo University. The thermal neutron flux density was $4.5 \times 10^{14}$ and $3.24 \times 10^{16} \mathrm{n} / \mathrm{cm}^{2}$ for short- and long-lived nuclides, respectively. The $\gamma$-ray intensities from short-and longlived nuclides were measured for $600 \mathrm{~s}$ and $3000 \mathrm{~s}(1800 \mathrm{~s}$ in the case of standards), respectively, by the Ge $\gamma$-ray spectrometer with $1.7 \mathrm{keV}$ full width at half maximum resolution at $1332 \mathrm{keV}$.

\section{Results and Discussion}

\section{Dispersion of activated-carbon powder}

The distribution of the elements in the standard samples influences their XRF intensities. Cyclohexane, acetone, distilled water and a $0.01 \%$ surfactant (Tween 85) solution was examined as a dispersant for the homogeneous dispersion of activated-carbon powder and elements. The standard solutions containing the elements $50 \mu \mathrm{g}$ each and $1.5 \mathrm{ml}$ of each dispersant were added to $10.0 \mathrm{mg}$ of a fine powder of activated carbon. The thin-layer samples were then prepared according to the recommended procedure. Cyclohexane and acetone caused significant loss of the solvent, because these solvents could not be held on the activated carbon. Distilled water dispersed activated-carbon powder homogeneously, but caused an uneven sample surface during drying. A $0.01 \%$ surfactant (Tween 85 ) solution did not cause any of the above-mentioned problems. Therefore, the surfactant solution was selected as the dispersant for the recommended procedure, and was effective for one month after being prepared. Furthermore, the optimum dispersing time was examined using the surfactant solution. Dispersing times of 2-3,5-6 and 10-11 min had almost the same effect on the dispersion of carbon powder and XRF intensities. Therefore, 2-3 min were adopted as the dispersing time in the recommended procedure.

\section{Recovery tests of elements}

Standard samples were prepared according to the recommended procedure, except for the lack of a fixative, and their XRF intensities were measured. Elements in the samples were eluted by heating with $5.0 \mathrm{ml}$ of $\mathrm{HNO}_{3}$ in a 100 -ml beaker at $60-70^{\circ} \mathrm{C}$ for about 
Table 2 Recovery tests of elements in the standard samples by ICP-AES

\begin{tabular}{lrrrrrrrrrr}
\hline & $\mathrm{Na}$ & $\mathrm{Mg}$ & $\mathrm{Al}$ & $\mathrm{K}$ & $\mathrm{Ca}$ & $\mathrm{Fe}$ & $\mathrm{Co}$ & $\mathrm{Ni}$ & $\mathrm{Cu}$ & $\mathrm{Zn}$ \\
\hline Added $/ \mu \mathrm{g}$ & 50 & 50 & 50 & 50 & 50 & 50 & 50 & 50 & 50 & 50 \\
Found $/ \mu \mathrm{g}$ & 46 & 50 & 50 & 45 & 50 & 50 & $\mathbf{4 5}$ & $\mathbf{4 8}$ & $\mathbf{4 6}$ & 49 \\
Recovery, \% & 92 & 100 & 100 & 90 & 100 & 100 & 90 & 96 & 92 & 98 \\
\hline
\end{tabular}

10 min. After cooling, the filter was picked up with a pair of PTFE-coated tweezers, washed with $\mathrm{HNO}_{3}$ and removed. Then, $250 \mu \mathrm{l}$ of a yttrium standard solution $\left(1.0 \mathrm{mg} \mathrm{ml}^{-1}\right)$ was added to the solution, which was then diluted to $50 \mathrm{ml}$ with water to be subject to ICP-AES using a yttrium internal standard. The recoveries of the measured elements, i.e., sodium, magnesium, aluminum, potassium, calcium, iron, cobalt, nickel, copper and zinc were $90-100 \%$, as shown in Table 2 .

\section{Fixation of activated-carbon powder}

Standard samples must have good resistance against $\mathrm{X}$-ray irradiation as well as stability. Therefore, polycarbonate, poly(methyl metacrylate) and cellulose acetate were compared as a fixative for improving the resistance against X-ray irradiation and the easiness of handling. The standard samples (group 1) were prepared by using these fixatives according to the recommended procedure, and the relative standard deviations (RSDs) of their XRF intensities were measured. Figure 2 shows the effect of the fixative on the XRF intensities of some elements of $50 \mu \mathrm{g}$ each. Reasonable precisions of $2-7 \%$ were obtained when using polycarbonate for all of the elements examined. The highest intensities were also obtained in this case, except for silicon. Since dichloromethane is more volatile than acetone, its solution allowed an easy and rapid formation of a homogeneous sample. An acetone solution caused a redispersion of activated carbon, and gave a heterogeneous sample. Poly(methyl methacrylate) and cellulose acetate could not successfully fix activated carbon on the filter, and could not be used to prepare stable samples. Therefore, the polycarbonate dichloromethane solution was adopted in the recommended procedure.

\section{Reproducibility of $X R F$ intensities}

The reproducibility of the XRF intensities of 21 elements of $50 \mu \mathrm{g}$ each in the samples prepared repeatedly according to the recommended procedure was examined. Reasonable precisions of $2.3-8.9 \%$ were obtained for all of the elements, as shown in Table 3.

\section{Effects of the particle size and amount of activated carbon on the XRF intensities}

Standard solutions containing elements of $50 \mu \mathrm{g}$ each and a surfactant solution of $1.5 \mathrm{ml}$ were added to fine $(<1.0 \mu \mathrm{m})$ and coarse $(<10-20 \mu \mathrm{m})$ powders of activated carbon of $2.0,5.0$ and $10.0 \mathrm{mg}$. Standard samples were prepared according to the recommended procedure, and

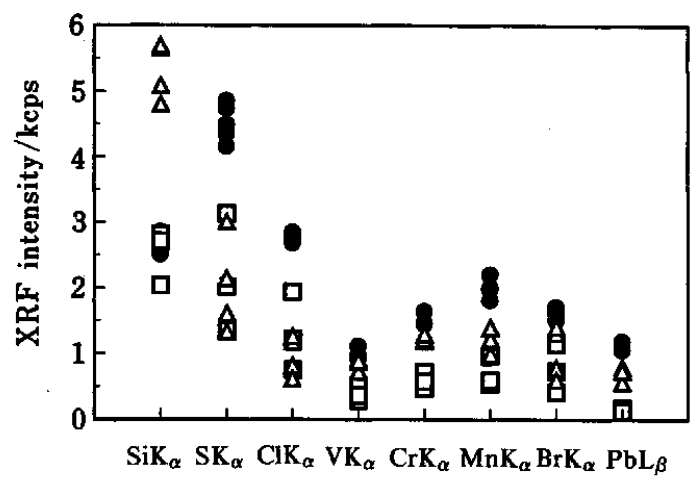

Fig. 2 Effect of a fixative of activated carbon on XRF intensities of each element of $50 \mu \mathrm{g}$. Fixative $(0.3 \mathrm{ml}):$ $0.02 \%$ polycarbonate dichloromethane solution; $\Delta, 0.02 \%$ poly(methyl methacrylate) acetone solution; $\square, 0.02 \%$ cellulose acetate acetone solution. Activated carbon, $10.0 \mathrm{mg}$.

Table 3 RSDs of XRF intensities of elements of $50 \mu \mathrm{g}$ each in the standard samples

\begin{tabular}{ccc}
\hline Characteristic X-ray & Analyzing crystal & RSD $^{\mathrm{a}}, \%$ \\
\hline $\mathrm{Si} \mathrm{K}_{\alpha}$ & $\mathrm{PET}$ & 4.6 \\
$\mathrm{~S} \mathrm{~K}_{\alpha}$ & $\mathrm{PET}$ & 5.6 \\
$\mathrm{Cl} \mathrm{K}$ & $\mathrm{PET}$ & 2.3 \\
$\mathrm{~V} \mathrm{~K}_{\alpha}$ & $\mathrm{LiF}$ & 6.7 \\
$\mathrm{Cr} \mathrm{K}$ & $\mathrm{LiF}$ & 4.8 \\
$\mathrm{Mn} \mathrm{K}_{\alpha}$ & $\mathrm{LiF}$ & 6.3 \\
$\mathrm{Br} \mathrm{K}_{\alpha}$ & $\mathrm{LiF}$ & 3.8 \\
$\mathrm{~Pb} \mathrm{~L}_{\beta}$ & $\mathrm{LiF}$ & 5.0 \\
$\mathrm{Na} \mathrm{K}_{\alpha}$ & $\mathrm{TAP}$ & 3.7 \\
$\mathrm{Mg} \mathrm{K}_{\alpha}$ & $\mathrm{TAP}$ & 8.9 \\
$\mathrm{Al} \mathrm{K}_{\alpha}$ & $\mathrm{PET}$ & 5.9 \\
$\mathrm{~K} \mathrm{~K}_{\alpha}$ & $\mathrm{PET}$ & 6.6 \\
$\mathrm{Ca} \mathrm{K}_{\alpha}$ & $\mathrm{PET}$ & 6.6 \\
$\mathrm{Ti} \mathrm{K}_{\alpha}$ & $\mathrm{LiF}$ & 7.4 \\
$\mathrm{Fe} \mathrm{K}_{\alpha}$ & $\mathrm{LiF}$ & 7.9 \\
$\mathrm{Co} \mathrm{K}$ & $\mathrm{LiF}$ & 8.2 \\
$\mathrm{Ni} \mathrm{K}_{\alpha}$ & $\mathrm{LiF}$ & 8.1 \\
$\mathrm{Cu} \mathrm{K}$ & $\mathrm{LiF}$ & 6.8 \\
$\mathrm{Zn} \mathrm{K}$ & $\mathrm{LiF}$ & 5.6 \\
$\mathrm{As} \mathrm{K}$ & $\mathrm{LiF}$ & 7.2 \\
$\mathrm{Cd} \mathrm{L}$ & $\mathrm{PET}$ & 4.4 \\
\hline
\end{tabular}

a. Calculated from XRF measurements of five samples prepared for the same composition. Fine powder of activated carbon: $10.0 \mathrm{mg}$.

subjected to XRF analysis. Figures 3 and 4 show the effects of the particle size and amount of activated carbon on the XRF intensities. The XRF intensities of samples prepared by using fine powder of $5.0 \mathrm{mg}$ were normalized as 1. Samples prepared by using especially small amounts of coarse powder gave low intensities, especially for X-rays of longer wavelengths. Samples prepared by using $2.0 \mathrm{mg}$ of fine powder showed a few low intensities for silicon and sulfur. Therefore, $5-10 \mathrm{mg}$ of fine powder 

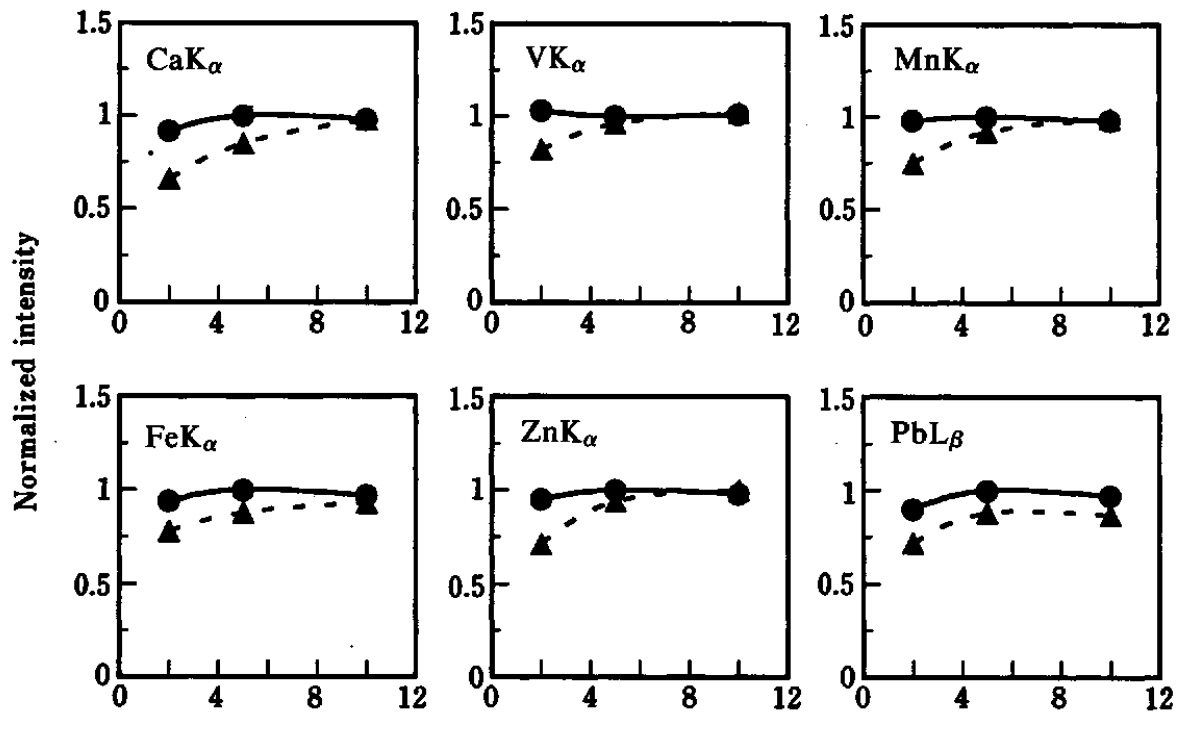

Activated carbon/mg

Fig. 3 Effects of the particle size and amount of activated carbon on XRF intensities of heavier elements. Added amount of each element, $50 \mu \mathrm{g}$; particle size: $\bullet,<1.0 \mu \mathrm{m} ; \Delta,<10-20 \mu \mathrm{m}$.
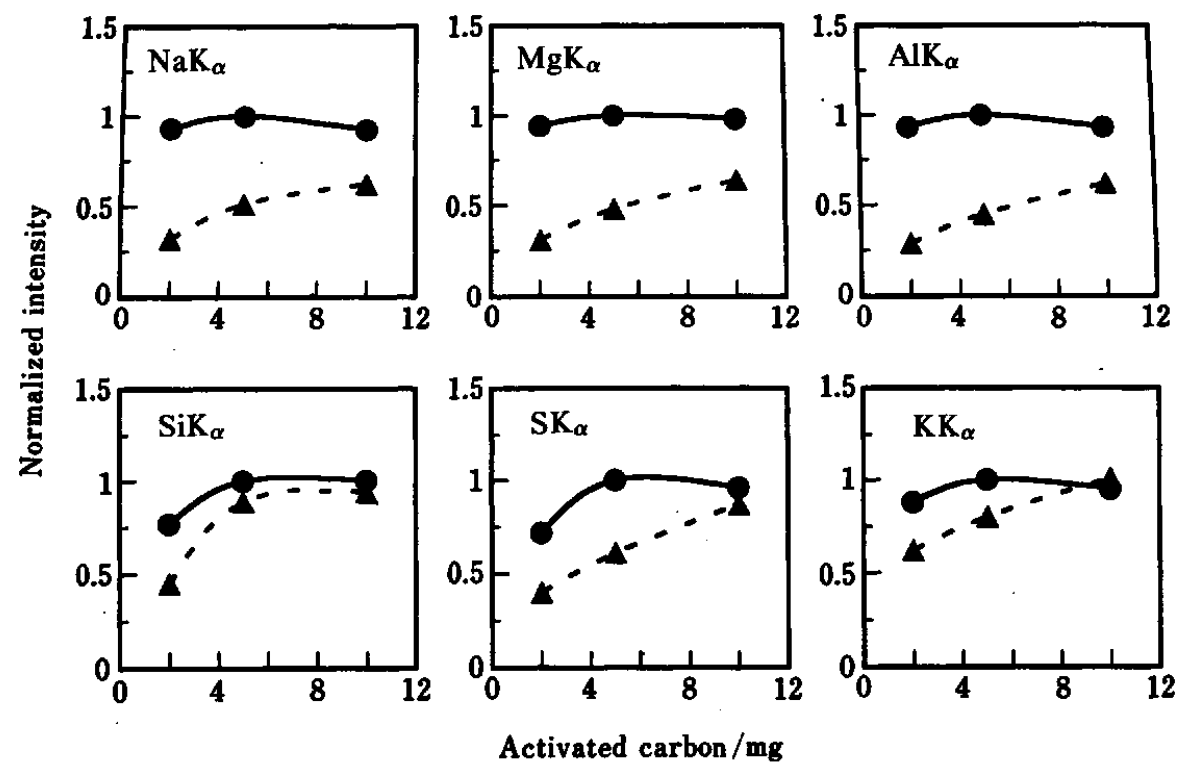

Fig. 4 Effects of the particle size and amount of activated carbon on XRF intensities of lighter elements. Added amount of each element, $50 \mu \mathrm{g}$; particle size: $0,<1.0 \mu \mathrm{m} ; \Delta,<10-20 \mu \mathrm{m}$.

of activated carbon was used in the recommended procedure.

\section{Calibration graphs}

Calibration graphs were constructed in the range of $0-50 \mu \mathrm{g}$ for all of the elements by using $5.0 \mathrm{mg}$ of fine powder of activated carbon. These calibration graphs showed good linear relationships and reasonable precision, as shown in Table 4.
Application to real samples and a comparison with analytical results by INAA

A multi-element determination of airborne particulate matter collected on filters was carried out for all elements shown in Table 4 by the XRF method using standard samples prepared by the present method. In order to improve the resistance of a cellulose nitrate filter against $\mathrm{X}$-ray irradiation, the filter with a sample was backed with adhesive polypropylene film, and mounted on a paper ring (40 and $50 \mathrm{~mm}$ in inside and outside diameters, 
Table 4 Equations of calibration graphs and their correlation coefficients $(r)$

\begin{tabular}{|c|c|c|c|}
\hline $\begin{array}{c}\text { Characteristic } \\
\text { X-ray }\end{array}$ & $\begin{array}{l}\text { Analyzing } \\
\text { crystal }\end{array}$ & Equation $(y=)$ & $r$ \\
\hline \multicolumn{4}{|l|}{ (a) Group 1} \\
\hline $\operatorname{Si~} K_{\alpha}$ & PET & $4.46 \times 10^{-2} x+0.49$ & 0.9978 \\
\hline $\mathrm{S} \mathrm{K}_{\alpha}$ & PET & $8.21 \times 10^{-2} x+0.26$ & 0.9972 \\
\hline $\mathrm{Cl} \mathrm{K} \mathrm{\alpha}_{\alpha}$ & PET & $4.01 \times 10^{-2} x+0.75$ & 0.9881 \\
\hline $\mathrm{V} \mathbf{K}_{\alpha}$ & LiF & $2.03 \times 10^{-2} x+0.01$ & 0.9971 \\
\hline $\operatorname{Cr~K}_{\alpha}$ & $\mathrm{LiF}$ & $3.12 \times 10^{-2} x+0.02$ & 0.9948 \\
\hline $\mathrm{Mn} \mathrm{K}_{\alpha}$ & $\mathrm{LiF}$ & $4.17 \times 10^{-2} x+0.08$ & 0.9882 \\
\hline $\operatorname{Br} \mathbf{K}_{\alpha}$ & $\mathbf{L i F}$ & $3.07 \times 10^{-2} x+0.16$ & 0.9939 \\
\hline $\mathrm{Pb} \mathrm{L}_{\beta}$ & $\mathrm{LiF}$ & $1.93 \times 10^{-2} x+0.01$ & 0.9932 \\
\hline \multicolumn{4}{|l|}{ (b) Group } \\
\hline $\mathrm{Na} \mathrm{K} \boldsymbol{\alpha}$ & TAP & $1.35 \times 10^{-2} x+0.03$ & 0.9998 \\
\hline $\mathrm{Mg} \mathrm{K}_{\alpha}$ & TAP & $2.63 \times 10^{-2} x+0.07$ & 0.9991 \\
\hline $\mathrm{Al} \mathrm{K}$ & PET & $2.81 \times 10^{-2} x+0.32$ & 0.9991 \\
\hline $\mathbf{K} \mathbf{K}_{\boldsymbol{\alpha}}$ & PET & $3.84 \times 10^{-2} x+0.39$ & 0.9951 \\
\hline $\mathrm{Ca} \mathrm{K}_{\alpha}$ & PET & $4.10 \times 10^{-2} x+0.24$ & 0.9871 \\
\hline $\operatorname{Ti} \mathbf{K}_{\alpha}$ & $\mathrm{LiF}$ & $1.33 \times 10^{-2} x+0.04$ & 0.9930 \\
\hline $\mathrm{Fe} \mathrm{K}_{\alpha}$ & LiF & $4.33 \times 10^{-2} x+0.23$ & 0.9933 \\
\hline $\mathrm{Co} \mathrm{K}_{\alpha}$ & $\mathrm{LiF}$ & $4.79 \times 10^{-2} x+0.13$ & 0.9931 \\
\hline $\mathrm{Ni} \mathrm{K}_{\boldsymbol{\alpha}}$ & $\mathrm{LiF}$ & $5.30 \times 10^{-2} x+0.22$ & 0.9922 \\
\hline $\mathrm{Cu} \mathrm{K}_{\alpha}$ & LiF & $5.67 \times 10^{-2} x+0.13$ & 0.9921 \\
\hline $\mathrm{Zn} \mathrm{K} \mathrm{K}_{\alpha}$ & $\mathrm{LiF}$ & $5.65 \times 10^{-2} x+0.16$ & 0.9981 \\
\hline As $K_{\alpha}$ & $\mathrm{LiF}$ & $5.44 \times 10^{-2} x+0.16$ & 0.9893 \\
\hline $\operatorname{Cd} L_{\alpha}$ & PET & $0.39 \times 10^{-2} x+0.10$ & 0.9829 \\
\hline
\end{tabular}

$y$ : XRF intensity/kcps; $x$ : content $/ \mu \mathrm{g}$.

For the group 1 or 2 , six samples containing 0 (blank), 10, 20, 30,40 or $50 \mu \mathrm{g}$ of each element were used. respectively; $0.7 \mathrm{~mm}$ thick) for easy handling. This backing was not necessary for hydrophilized PTFE and regenerated cellulose filters. The XRF intensities of the prepared samples were measured under the conditions described above. The blank XRF intensities of the polypropylene film used were negligible. Since the used samples were very thin $\left(20-330 \mu \mathrm{g} / \mathrm{cm}^{2}\right)$, the amounts of the elements were determined from the measured XRF intensities without any matrix correction ${ }^{6}$ by using the prepared calibration graphs. Table 5 shows the results of the multi-element determination of several samples which were simply and successfully obtained by the XRF method. Although bromine could not be determined for the samples on cellulose nitrate filters, because of high filter blank values, it could be determined for those on other filters. Although nickel, arsenic and cadmium were not detected in these samples, these elements can also be determined, if sufficient amounts of elements are collected.

For checking the reliability of the XRF data, INAA was carried out for 11 elements in some samples under the above-mentioned conditions. Both the XRF and the INAA data of the same samples were converted into concentrations in air to compare with each other. As shown in Fig. 5, the analytical results of sodium, aluminum, calcium, titanium, manganese, iron, copper and zinc determined by the XRF method were in good agreement with those obtained by INAA. This agreement suggests that the matrix effects in the XRF
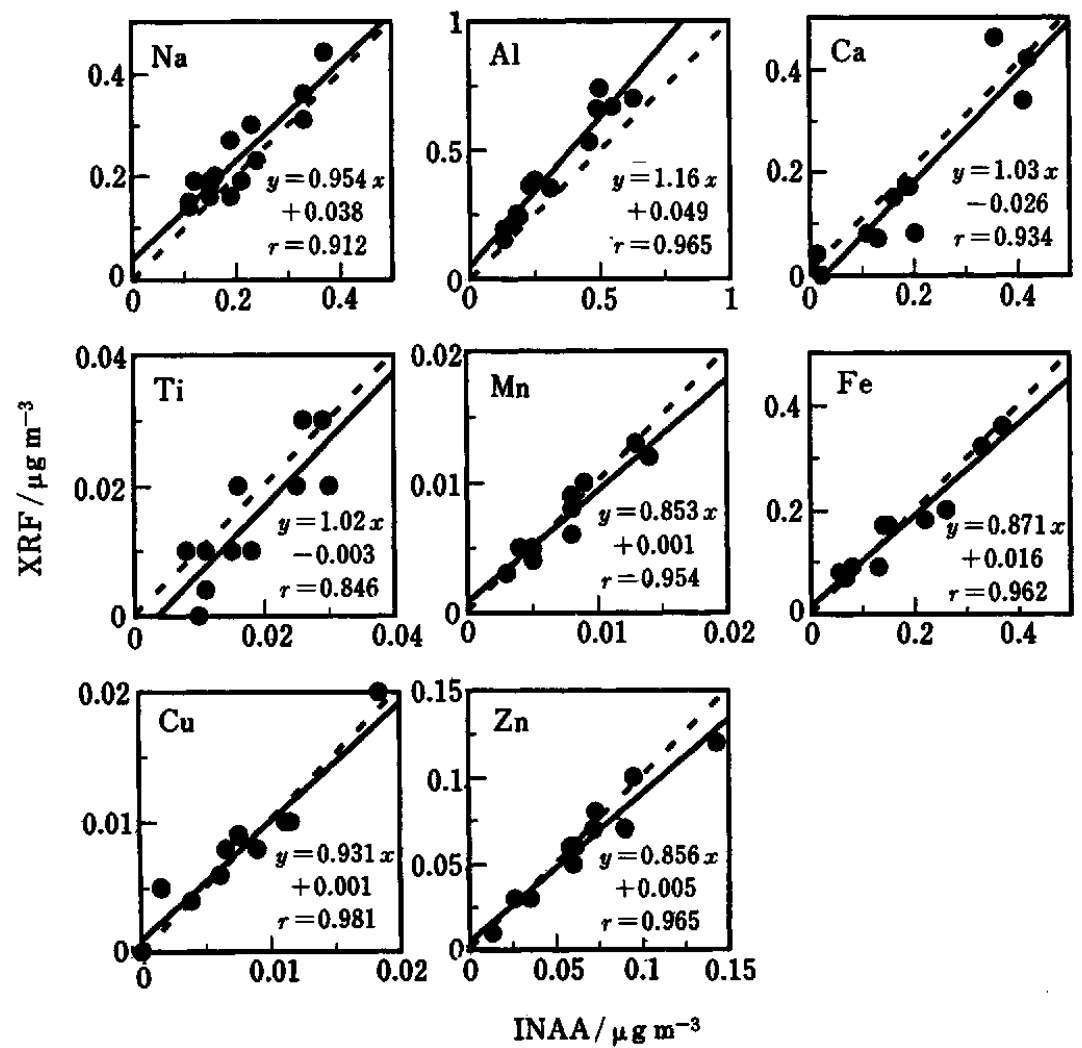

Fig. 5 Comparison between the analytical results obtained by XRF and INAA. 
Table 5 Examples of analytical results (mass on filter $/ \mu \mathrm{g} \mathrm{cm}^{-2}$ ) of airborne particulate samples by the XRF method using standard samples prepared by the present method

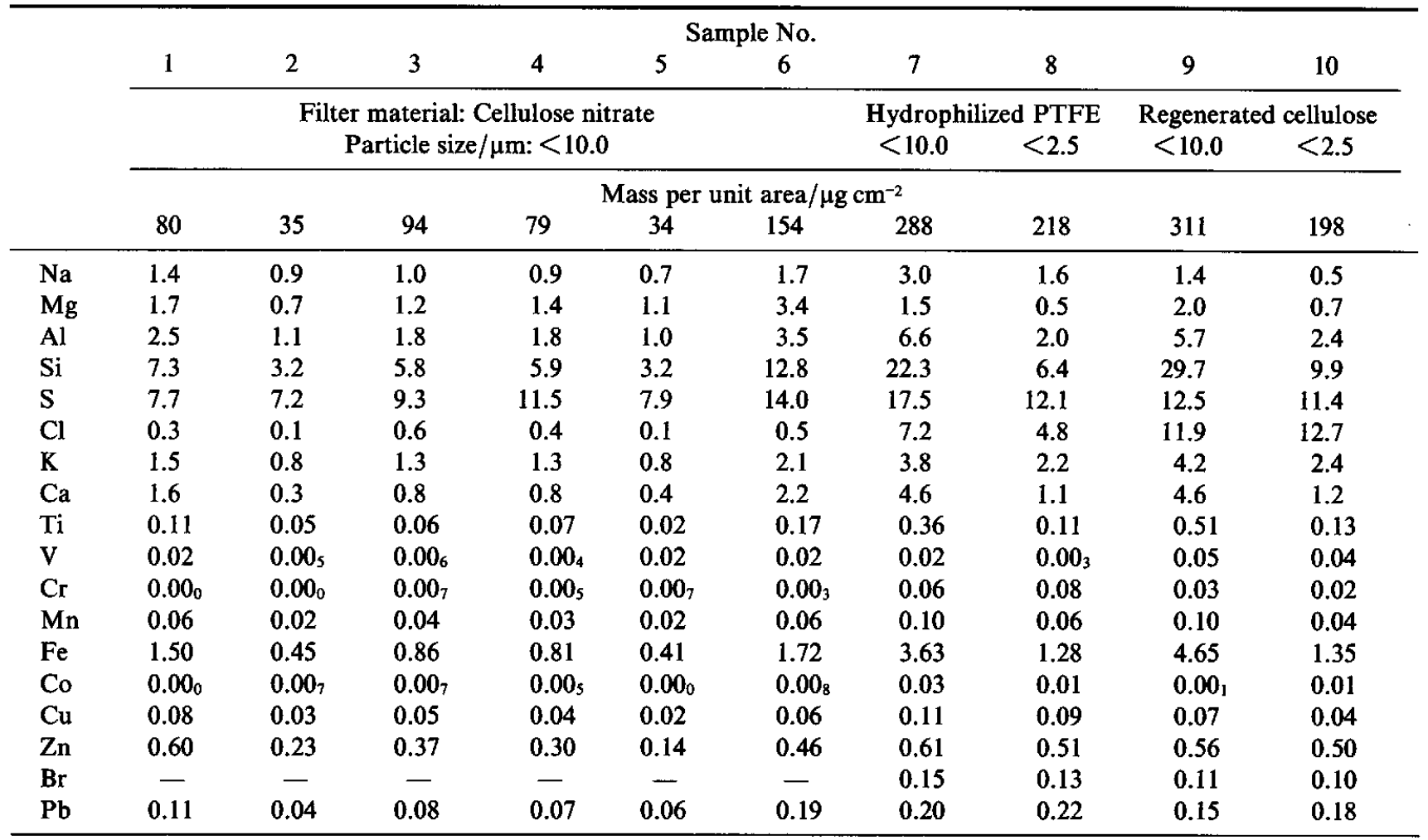

Refer to the text for the sampling conditions. Sample Nos. $1-6$ were backed with adhesive polypropylene film before X-ray measurements. - , not determined bacause of high filter blank value. $\mathrm{Ni}$, As and $\mathrm{Cd}$ were not detected in the samples used.

intensity measurements can be neglected in these samples. Vanadium and cobalt could not be compared, because of trace amounts near to their detection limits in the samples used for the comparison, and also bromine because of high filter blank values. Thus, the standard samples prepared by the present method were successfully used for the multi-element XRF determination of airborne particulate matter collected as a thin layer on a filter.

\section{References}

1. T. Otoshi, Y. Izumikawa, M. Fujimura and Y. Hashimoto, Environ. Sci., 2, 89 (1993).

2. T. Shono and K. Shinra, Bunseki Kagaku, 18, 1032(1969).

3. D. E. Kimbrough and I. H. M. Suffet, Analyst [London], 121, 309 (1996).

4. C. F. Wang, E. E. Chang, P. C. Chiang and N. K. Aras, Analyst [London], 120, 2521 (1995).

5. K. Ohno, H. Sasuga, T. Muramatsu, M. Yasuno, Y. Kawabe and K. Oikawa, Kogai to Taisaku, 13, 144 (1977).

6. Y. Nogami, M. Fujimura, H. Morii and Y. Hashimoto, Bunseki Kagaku, 29, T85 (1980).

7. M. Matsumoto, H. Ichikawa, K. Ichimura, E. Ueda and T. Itano, Zenkoku Kogaiken Kaishi, 7, 95 (1982).

8. R. Chakravorty and R. Van Grieken, Intern. J. Environ. Anal. Chem., 11, 67 (1982).
9. S. Tanaka, S. Sato, Y. Nogami, K. Okimine, K. Matsumoto, Y. Gohshi and Y. Hashimoto, Taiki Osen Gakkaishi, 22, 301 (1987).

10. K. Himi and T. Muramatsu, Taiki Osen Kenkyu, 10, 135 (1975).

11. J. V. Gilfrich, P. G. Burkhalter and L. S. Birks, Anal. Chem., 45, 2002 (1973).

12. O. Haupt, B. Klaue, C. Schaefer and W. Dannecker, $X$ Ray Spectrom., 24, 267 (1995).

13. O. Haupt, C. Schaefer, S. Strauss and W. Dannecker, Fresenius' J. Anal. Chem., 355, 375 (1996).

14. R. B. Kellogg, N. F. Roache and B. Dellinger, Anal. Chem., 53, 546 (1981).

15. B. E. Artz and H. Chessin, Adv. X-Ray Anal., 17, 225 (1974).

16. T. G. Dzubay, N. Morosoff, G. L. Whitaker, H. Yasuda, F. Bazan, R. L. Bennett, J. Cooper, W. J. Courtney, C. A. Frazier, et al., J. Trace Microprobe Tech, 5, 327 (1987).

17. T. W. S. Pang, A. M. D'Onofrio, F. B. Lo, D. K. Arai and M. A. Nazar, $X$-Ray Spectrom., 16, 45 (1987).

18. W. K. Stankiewicz, Z. A. Mzyk and B. M. Roter, Mikrochim. Acta, 123, 137 (1996).

19. J. Billiet, R. Dams and J. Hoste, X-Ray Spectrom., 9, 206 (1980).

20. T. Otoshi, T. Shiomi, K. Tomura and Y. Hashimoto, Bunseki Kagaku, 25, 620 (1976).

(Received May 6, 1997)

(Accepted July 22, 1997) 